\title{
Evaluation of Cardiovascular Risk Factors in HIV/AIDS Patients Attending the Tiko Central Clinic and Cottage Hospital, Tiko, Cameroon
}

\author{
Jules CN Assob ${ }^{1,2 *}$, Vigny Njeodo ${ }^{1}$, Vincent S Verla ${ }^{3}$, John F Tengen ${ }^{3}$, Peter Ayuk ${ }^{1}$ and Eric A Achidi ${ }^{4}$ \\ ${ }^{1}$ Department of Medical Laboratory Science, Faculty of Health Sciences, University of Buea, Cameroon
}

${ }^{2}$ Department of Biomedical Sciences, Faculty of Health Sciences, University of Buea, Cameroon

${ }^{3}$ Department of Internal Medicine and Paediatrics, Faculty of Health Sciences, University of Buea, Cameroon

${ }^{4}$ Department of Biochemistry and Molecular biology, Faculty of Science, University of Buea, Cameroon

*Corresponding author: Jules CN Assob, Department of Medical Research and Applied Biochemistry Laboratory, Biomedical Sciences, Faculty of Health Sciences, University of Buea, Cameroon.

\begin{abstract}
The introduction of highly active antiretroviral therapy (HAART) in 1995 has led to a significant fall in mortality observed in human immunodeficiency virus (HIV) infected patients and a noticeable decrease in opportunistic infections. However, metabolic complications associated with HAART and HIV increase the risk of developing a cardiovascular disease (CVD). This study was aimed at evaluating the risk factors associated with cardiovascular diseases amongst persons living with HIV. This was a hospital-based case-control study. Cases were HIV sero-positive persons on HAART for at least 6 months and controls were HIV sero-negative persons. Recruitment was consecutive and online DAD and QRISK calculators were used to determine the 5- and 10-year risk of cardiovascular events respectively. Out of 135 participants, 74 (54.8\%) were females amongst which $53 / 75(71.6 \%)$ were in the control group and $21 / 60(28.4 \%)$ were in the cases group. The mean age of the participants was $42.04( \pm 9.61)$ years. The most common cardiovascular risk factors in both the cases and control groups were decreased High Density Lipoprotein cholesterol HDL-c (84.4\%), insufficient fruit or vegetable consumption (68.9\%), and obesity or overweight (45.9\%). A lower proportion of participants, 75\% (39/52) in the HAART regimen class, Tenofovir/Lamivudine/Efavirenz were at low CVD risk based on the D.A.D risk calculator compared to 78\% (14/18) of those in the Zidovudine/Lamivudine /Nevirapine class. Also, more participants (23\%) on Tenofovir/Lamivudine/Efavirenz were at moderate risk compared to those (22\%) on Zidovudine/Lamivudine/Nevirapine. Using the QRISK®2-2016 equation, 6.7\% (5/75) of HAART, HIV patients had a moderate CVD risk unlike in the control group where 13.3\% (8/60) of the participants had a moderate CVD risk. On the contrary, the DAD risk equation revealed $25.3 \%$ of HAART HIV patients had a moderate CVD risk. DAD risk was higher in HIV patients who have been on HAART for more than 5 years. High Density Lipoprotein cholesterol, abnormal waist to hip ratio, abdominal obesity, obesity, and older age are more prevalent in HIV sero-positive individuals on HAART than in HIV sero-negative people. The DAD risk calculator is a suitable predictor of cardiovascular disease for HIV patients on HAART. Risk of coronary heart disease increases and is higher with Tenofovir/ Lamivudine/Efavirenz HAART regimen and with being on HAART for more than 60 months respectively.
\end{abstract}

Keywords: Cardiovascular disease; HAART; HIV risk equations; Risk factors

Abbreviations: 3TC: Lamivudine; Ab: Antibody; Ag: Antigen; AIDS: Acquired Immune Deficiency Syndrome; ART: Antiretroviral Therapy; AZT: Zidovudine; BMI: Body Mass Index; CD4+: Cluster of Differentiation ; CETP: Cholesterol Transfer Protein; CVD: Cardiovascular disease; DAD: Data collected on Adverse effects of anti-HIV Drugs; DBP: Diastolic Blood Pressure; EFV: Efavirenz; FBS: Fasting Blood Sugar; HAART: Highly; Active Antiretroviral Therapy; HC: Hip Circumference; HDL-c: High Density Lipoprotein cholesterol; HIV: Human Immunodeficiency Virus; LDL-c: Low Density Lipoprotein cholesterol; LPV: Lopinavir; NNRTIs: Non-Nucleoside Reverse Transcriptase Inhibitors; NRTIs: Nucleoside Reverse Transcriptase Inhibitors; NVP: Nevirapine; RTV: Ritonavir; PI: Protease Inhibitor; SBP: Systolic Blood Pressure; SPSS: Statistical Package for Social Sciences; TC: Total cholesterol; TGs: Triglycerides; VLDL-c: Very Low Density Lipoprotein cholesterol; WC: Waist circumference; WHR: Waist to Hip Ratio

\section{Introduction}

Theintroduction of HAART (Highly active antiretroviral therapy) in 1995 has resulted in a significant fall in mortality observed in
HIV (Human immunodeficiency virus) positive patients and a significant decrease in the incidence of opportunistic infections alongside HIV related cancers [1]. However, ART (Antiretroviral 
therapy) and HIV are associated with metabolic complications that increase the risk of developing cardiovascular diseases (CVD) [2]. The metabolic complications associated with the use of HAART include dyslipidaemia, lipodystrophy, and insulin resistance [3]. Australian investigators in 2014 reported that Lipid disorders in HIV sero-positive persons are largely mediated by ART and those associated with nucleoside reverse transcriptase inhibitors (NRTIs) are mild relative to non-nucleoside reverse transcriptase inhibitors (NNRTIs) and Protease inhibitors (PIs) - which are associated with elevated VLDL, LDL-c, and TGs [4]. HAART consisting of efavirenz and 2 NRTIs (zidovudine or stavudine/ lamivudine) has been reported to cause a higher incidence of lipoatrophy relative to the HAART regimen, lopinavir (LPV) and 2 NRTIs (tenofovir/lamivudine) [5]. Busari and colleagues in 2009 reported that insulin resistance is mediated precisely by protease inhibitors such as LPV, ritonavir including NRTIs [6]. The prevalence of risk factors associated with cardiovascular diseases and cardiovascular risk status in HAART treated HIV sero-positive patients were reported by investigators in Polokwane, South Africa and by Nguedia and others in Buea, Cameroon [7]. In Cameroon, despite an increase in HIV prevalence, little is known about the prevalence of cardiovascular risk factors and total cardiovascular risk in these patients. Arguably this has limited the therapeutic and lifestyle interventions geared towards these factors with a view of preventing cardiovascular events. In light of this, we therefore sought to determine the prevalence of cardiovascular risk factors and risk status in HIV sero-positive subjects attending the Tiko Central Clinic and Cottage hospital in Cameroon.

\section{Methods}

This study was conducted over a four-month period, from March to June 2016, at the treatment centre of people living with HIV/AIDS, at the Tiko Central Clinic and Cottage hospital. Over 1500 patients receive their treatment from these centres. The patients attend the clinic once a month for clinical evaluation and refill of ART. A consecutive sampling technique was employed because recruitment of all available participants into this study was based on meeting the inclusion and exclusion criteria. The goals of the study, research procedure, risks and benefits of this research were explained to the study respondents and only participants who gave consent were included in the study. Specimens and results were coded. The study population included all adult HIV sero-positive and HIV sero-negative persons attending the Tiko Central Clinic and Cottage hospital for routine health assessment. We included all people living with HIV/AIDS (PLWHA) aged at least 25 years and excluded patients less than 25 years of age, those on highly active anti-retroviral therapy (HAART) for less than 6 months including defaulters of treatment regimen, pregnant and lactating women, those with documented hypertension, diabetes and dyslipidaemia before commencing HAART and those with any acute illness that required medical/surgical treatment or admission. HAART was defined as the use of $\geq 2$ nucleoside reverse transcriptase inhibitors (NRTIs) and at least one non-nucleoside reverse transcriptase inhibitor (NNRTI); or $\geq 2$ NRTIs and at least one protease inhibitor
(PI). A structured questionnaire was used to collect sociodemographic data from the participants while their medical records were accessed to obtain clinical information such as their recent CD4+ T cell count, HIV status, type and duration of HAART regimen. Following a 10-minute resting period, while participant was seated, 2 blood pressure measurements (systolic and diastolic) were taken in the left arm with an interval of 3 minutes using a wrist digital blood pressure monitor. The average blood pressure reading was calculated and used as the participants' actual blood pressure. Waist circumference (WC) was measured to the nearest $0.1 \mathrm{~cm}$ with patients wearing light clothing at the midpoint between the lowest rib and the iliac crest using an inelastic tape in light contact with but not compressing the skin. Hip circumference (HC) was also measured with an inelastic tape around the widest portion of the buttocks in light clothing to the nearest $0.1 \mathrm{~cm}$. The waist-to-hip ratio was then calculated by dividing the WC by HC. The weight of each participant was measured using a Kinlee calibrated weighing scale in light clothing, with shoes off. Height was measured using a stadiometer to the nearest $0.1 \mathrm{~cm}$.

Following this, $3 \mathrm{ml}$ of venous blood was obtained, under strict asepsis, after an overnight fast (8-12 hours). Fasting blood glucose was measured using the Accu Chek® Compact Plus glucometer at the spot. Serum was then collected and stored in eppendorf tubes until analysis. Lipid profiles of the participants' sera were later measured in batches using a MINDARY spectrophotometer (BA-88A semi-auto chemistry analyser with touchscreen and pop-up keypad) according to the manufacturer's instruction. Triglycerides and total cholesterol levels were measured based on a Glycerol phosphate oxidase and Total Cholesterol oxidase methods respectively. HDL-C level was measured based on the Chemical precipitation technique in the presence of phosphotungstic acid and $\mathrm{Mg} 2+$ ions. Low density lipoprotein cholesterol was calculated using the Friedewald equation: $\mathrm{LDL}-\mathrm{C}=\mathrm{TC}-(\mathrm{TG} / 5+\mathrm{HDL}-\mathrm{C})$. In accordance with the US National Cholesterol Education Program, Adult Treatment Panel III (NCEP-ATP III) guidelines, abnormal lipid profile was defined as TC $\geq 200 \mathrm{mg} / \mathrm{dl}$, HDL-c < $40 \mathrm{mg} / \mathrm{dl}$, LDL-c $\geq 130 \mathrm{mg} / \mathrm{dl}, \mathrm{TG} \geq 150 \mathrm{mg} /$ $\mathrm{dl}$ and TC/HDL-c ratio $\geq 5$. Abdominal obesity was defined as WC $>$ $102 \mathrm{~cm}$ in men or WC $>88 \mathrm{~cm}$ in women. Overweight was defined as Body Mass Index (BMI) of $25-29.9 \mathrm{~kg} / \mathrm{m} 2$ and obesity, BMI of $\geq 30$ $\mathrm{kg} / \mathrm{m} 2$. Hypertension was defined as SBP $\geq 140 \mathrm{mmHg}$ and/or DBP $\geq 90 \mathrm{mmHg}$ or current use of anti-hypertensive drug and Diabetes was defined as FBS $\geq 126 \mathrm{mg} / \mathrm{dL}$. The following parameters were defined as follows: Physical inactivity (failure to engage in physical activities, recreation or work that lasted $<30$ mins per day for $<$ 3 times in a week), abnormal WHR ( $>0.85$ for females and $>0.95$ for males), insufficient fruit /vegetable consumption (failure to consume fruit or vegetable daily), alcohol excess ( $>7$ local beers for men and $>4$ local beers per week for women whereby 1 local beer $=28 \mathrm{~g}$ alcohol). Ethical approval was obtained from the Faculty of Health Sciences Institutional Review Board (FHSIRB) of the University of Buea, Cameroon (reference number: 2014-02-0514). Administrative authorizations were obtained from the following authorities: regional delegate of public health in Buea, district 
medical officer in Tiko, director of human resource in Limbe, and from the chief medical officer in Tiko. Data analysis was performed on SPSS version 21.0 using Student's " $t$ " test., Chi-square $(\chi 2)$ test and multivariate logistic regression. QRISK ${ }^{\circ} 2-2016$ risk calculator was used to determine the 10 -year risk of developing a coronary heart disease [8]. D.A.D (Data collection on Adverse events of antiHIV Drugs) risk

calculator was used to determine the 5-year risk of myocardial infarction, coronary heart disease and CVDs [9].

\section{Results}

A total of 135 participants were recruited, 75 (55.6\%) were HIV sero-positive amongst which $53(71.6 \%)$ were females and 60 (44.4\%) were HIV sero-negative amongst which 39 (63.9\%) were males. The mean age was $42.04( \pm 9.61)$ years in the HIV seropositive group and $39.00( \pm 11.3)$ years in the control group.

The median duration on HAART was $42.0(18$ - 82) months Table 1.

Table 1: Demographic characteristics of study population by HIV status.

\begin{tabular}{|c|c|c|c|c|}
\hline \multicolumn{2}{|c|}{ Parameter } & \multirow{2}{*}{$\begin{array}{l}\text { HIV Seropositive Group }(\mathbf{n}=\mathbf{7 5}) \\
\qquad 22(36.1)\end{array}$} & \multirow{2}{*}{$\begin{array}{l}\text { HIV Seronegative Group }(\mathrm{n}=\mathbf{6 0}) \\
39(63.9)\end{array}$} & \multirow{2}{*}{$\begin{array}{c}\text { Total } \\
61(45.2)\end{array}$} \\
\hline Condor & Male & & & \\
\hline Genaer & Female & $53(71.6)$ & $21(28.4)$ & $74(54.8)$ \\
\hline Age (years) & Mean \pm SD & $42.04 \pm 9.61$ & $39 \pm 11.3$ & $40.69 \pm 10.47$ \\
\hline \multirow[t]{4}{*}{ Occupation } & Salary employed & $43(48.9)$ & $45(51.1)$ & $88(65.2)$ \\
\hline & Self employed & $22(64.7)$ & $12(35.3)$ & $34(25.2)$ \\
\hline & Unemployed & $8(80.0)$ & $2(20.0)$ & $10(7.4)$ \\
\hline & Retired & $2(66.7)$ & $1(33.3)$ & $3(2.2)$ \\
\hline \multirow{3}{*}{ Marital status } & $\begin{array}{l}\text { Married/Cohabi- } \\
\text { tation }\end{array}$ & $38(50.7)$ & $33(55.0)$ & $71(52.6)$ \\
\hline & Single & $32(58.2)$ & $33(41.8)$ & $55(40.7)$ \\
\hline & Divorced & $5(55.6)$ & $4(44.4)$ & $9(6.7)$ \\
\hline \multirow{5}{*}{ Level of education } & $\begin{array}{l}\text { No formal edu- } \\
\text { cation }\end{array}$ & $4(44.4)$ & $5(55.6)$ & $9(6.7)$ \\
\hline & Primary & $39(58.2)$ & $28(41.8)$ & $67(49.6)$ \\
\hline & Secondary & $28(60.9)$ & 18(39.1) & $46(34.1)$ \\
\hline & Tertiary & $4(30.8)$ & $9(59.2)$ & $13(9.6)$ \\
\hline & Median (IQR) & $398(242-612)$ & - & - \\
\hline \multirow{3}{*}{ CD4+ T cell count* (cells $/ \mu \mathrm{L})$} & $<250$ & $17(23.6)$ & - & - \\
\hline & $250-500$ & $27(37.5)$ & - & - \\
\hline & $>500$ & $28(38.9)$ & - & - \\
\hline $\begin{array}{l}\text { Duration of HIV infection } \\
\text { (months) }\end{array}$ & Median (IQR) & $63(28-67)$ & - & - \\
\hline Duration of HAART (months) & Median (IQR) & $42(18-82)$ & - & - \\
\hline \multirow{5}{*}{ Type of HAART regimen } & $\mathrm{TDF}+3 \mathrm{TC}+\mathrm{EFV}$ & $47(69)$ & - & - \\
\hline & $\mathrm{AZT}+3 \mathrm{TC}+\mathrm{NVP}$ & $23(24)$ & - & - \\
\hline & $\mathrm{AZT}+3 \mathrm{TC}+\mathrm{EFV}$ & $2(3)$ & - & - \\
\hline & $\begin{array}{c}\mathrm{TD}- \\
\mathrm{F}+3 \mathrm{TC}+\mathrm{LPV}+\mathrm{RTV} \\
\end{array}$ & $2(3)$ & - & - \\
\hline & $\mathrm{TDF}+3 \mathrm{TC}+\mathrm{NVP}$ & $1(1)$ & - & - \\
\hline \multirow{6}{*}{$\begin{array}{l}\text { Number of participants by } \\
\text { HAART agent }\end{array}$} & $3 \mathrm{TC}$ & 75 & - & - \\
\hline & TDF & 55 & - & - \\
\hline & EFV & 54 & - & - \\
\hline & AZT & 20 & - & - \\
\hline & NVP & 19 & - & - \\
\hline & LPV+RTV & 2 & - & - \\
\hline
\end{tabular}

Key: HAART-Highly Active Antiretroviral therapy, ${ }^{*} \mathrm{CD} 4+\mathrm{T}$ cell count available only for 72 participants,

${ }^{*}$ Number of participants by HAART agent (No)

The proportion of participants with low HDL-c was significantly higher in the HIV infected group compared to the HIV uninfected group (OR: 38.17, $\mathrm{p}=<0.001$ ). Abnormal waist to hip ratio (WHR) was found in $61 / 135$ (45.2\%) participants with it being significantly higher in the HIV positive group compared to the control group (OR: $2.21, \mathrm{P}=0.035$ ). More abdominal obesity was more observed in the case group $28 / 75$ (37.3\%) compared to the control group $13 / 60(21.7 \%)$ Table 2 . 
Table 2: Proportion of CV risk factors in the study population based on HIV status.

\begin{tabular}{|c|c|c|c|c|c|c|c|}
\hline \multicolumn{2}{|c|}{ Cardiovascular Risk Factor } & HIV Seropositive $(n=75)$ & HIV Seronegative $(n=60)$ & Total & OR $(95 \% \mathrm{CI})$ & $X^{2}$ & P-value \\
\hline \multicolumn{2}{|c|}{ Hypercholesterolemia } & 0 & 2 & 2 & 1.4E7(1.4E7-1.4E7) & 2.538 & $<0.001$ \\
\hline \multicolumn{2}{|c|}{ Hypertriglyceridemia } & 3 & 12 & 15 & $6.00(1.61-22.39)$ & 8.64 & 0.008 \\
\hline \multicolumn{2}{|c|}{ Increased LDL-c } & 6 & 6 & 12 & $1.64(0.47-5.71)$ & 0.165 & 0.437 \\
\hline \multicolumn{2}{|c|}{ Low HDL-c } & 74 & 40 & 114 & $38.17(4.93-295.79)$ & 25.985 & $<0.001$ \\
\hline \multicolumn{2}{|c|}{ Obesity/Overweight } & 36 & 26 & 62 & $0.77(0.39-1.55)$ & 0.292 & 0.466 \\
\hline \multicolumn{2}{|c|}{ Diabetes mellitus } & 1 & 5 & 6 & $0.14(0.02-1.24)$ & 3.846 & 0.077 \\
\hline \multicolumn{2}{|c|}{ Hypertension } & 14 & 19 & 33 & $0.51(0.23-1.13)$ & 3.05 & 0.095 \\
\hline \multicolumn{2}{|c|}{ Alcohol excess } & 3 & 6 & 9 & $0.39(0.92-1.66)$ & 1.929 & 0.203 \\
\hline \multicolumn{2}{|c|}{ Older age } & 13 & 10 & 23 & $1.05(0.42-2.59)$ & 0.01 & 0.918 \\
\hline \multicolumn{2}{|c|}{ Physically inactive } & 6 & 7 & 13 & $1.52(0.48-4.78)$ & 0.515 & 0.476 \\
\hline \multicolumn{2}{|c|}{ Abnormal WHR } & 40 & 21 & 61 & $2.12(1.06-4.27)$ & 4.523 & 0.035 \\
\hline \multicolumn{2}{|c|}{ Abdominal obesity } & 28 & 13 & 41 & $2.15(1.00-4.66)$ & 3.869 & 0.051 \\
\hline \multicolumn{2}{|c|}{$\begin{array}{c}\text { Insufficient Fruit/Vegetable } \\
\text { consumption }\end{array}$} & 49 & 44 & 93 & \multirow{2}{*}{$1.46(0.69-3.09)$} & \multirow{2}{*}{0.995} & \multirow{2}{*}{0.323} \\
\hline \multicolumn{2}{|c|}{$\begin{array}{l}\text { Sufficient Fruit/Vegetable } \\
\text { consumption }\end{array}$} & 26 & 16 & 42 & & & \\
\hline \multicolumn{2}{|c|}{ Obesity } & 8 & 12 & 20 & $0.48(0.18-1.26)$ & 2.301 & 0.136 \\
\hline \multicolumn{2}{|c|}{ Family history } & 17 & 9 & 26 & \multirow{2}{*}{$1.69(0.69-4.18)$} & \multirow{2}{*}{1.26} & \multirow{2}{*}{0.253} \\
\hline \multicolumn{2}{|c|}{ No Family history } & 58 & 51 & 109 & & & \\
\hline \multirow[t]{2}{*}{ Smoking } & $\begin{array}{l}\text { Cur- } \\
\text { rent }\end{array}$ & 1 & 6 & 7 & \multirow[t]{2}{*}{$0.46(0.19-1.11)$} & \multirow[t]{2}{*}{5.61} & \multirow[t]{2}{*}{0.084} \\
\hline & Past & 9 & 9 & 18 & & & \\
\hline
\end{tabular}

Key: CV-Cardiovascular; OR-Odds ratio, $\mathrm{X}^{2}$-Chi square; WHR-Waist-hip ratio, HDL-c: High density lipoprotein cholesterol; LDL-c: Low density lipoprotein cholesterol, E7: $\times 10^{7}$

Older age (31.8 vs $11.3 \%, \mathrm{p}=0.033)$, and smoking $(12.0 \%$ vs $1.3 \%, \mathrm{p}=0.001$ ) were more frequent in males than females in the test group whereas abnormal WHR (9.1 vs 71.7\%, $\mathrm{p}=<0.001 ; 20.5$ vs $61.9 \%, \mathrm{p}=0.001$ ) and abdominal obesity (18.2 vs $45.3 \%, \mathrm{p}=$
0.027; 5.1 vs $52.4 \%, \mathrm{p}=<0.001$ ) were more observed in females, both in the HIV positive and control groups respectively Tables 3 and 4 .

Table 3: Proportion of CV risk factors in the test group based on gender.

\begin{tabular}{|c|c|c|c|c|c|c|}
\hline \multirow{2}{*}{ Cardiovascular Risk Factor } & \multicolumn{2}{|c|}{ HIV Seropositive } & \multirow{2}{*}{$\begin{array}{l}\text { Total } \\
N=75\end{array}$} & \multirow{2}{*}{$\begin{array}{c}\text { OR } \\
(95 \% \mathrm{CI})\end{array}$} & \multirow{2}{*}{$\mathbf{X}^{2}$} & \multirow{2}{*}{ P-value } \\
\hline & Males $(n=22)$ & Females $(n=53)$ & & & & \\
\hline Hypercholesterolemia & 0 & 0 & 0 & - & - & - \\
\hline Hypertriglyceridemia & 2 & 1 & 3 & $0.66(0.04-9.99)$ & 2.101 & 0.147 \\
\hline Increased LDL-c & 1 & 5 & 6 & $2.09(0.17-26.46)$ & 0.505 & 0.477 \\
\hline Low HDL-c & 22 & 52 & 74 & 7E5(7E5-7E5) & 0.421 & 0.517 \\
\hline Obesity/Overweight & 9 & 27 & 36 & $1.98(0.50-7.89)$ & 0.627 & 0.428 \\
\hline Diabetes mellitus & 0 & 1 & 1 & $8.7 \mathrm{E}-7(-)$ & 0.421 & 0.517 \\
\hline Hypertension & 6 & 8 & 14 & $3.51(0.61-20.11)$ & 1.519 & 0.218 \\
\hline Alcohol excess & 2 & 1 & 3 & $1.20(0.08-18.19)$ & 2.101 & 0.157 \\
\hline Older age & 7 & 6 & 13 & \multirow{2}{*}{$2.66(0.74-9.55)$} & \multirow{2}{*}{4.559} & \multirow{2}{*}{0.033} \\
\hline Younger age & 15 & 47 & 62 & & & \\
\hline Physically inactive & 2 & 4 & 6 & $0.89(0.12-6.19)$ & 0.05 & 0.822 \\
\hline Abnormal WHR & 2 & 38 & 40 & $0.04(0.01-0.22)$ & 24.484 & $<0.001$ \\
\hline Abdominal obesity & 4 & 24 & 28 & $0.46(0.13-1.66)$ & 4.881 & 0.027 \\
\hline Insufficient Fruit/Vegetable consumption & 16 & 33 & 49 & \multirow{2}{*}{$0.57(0.18-1.78)$} & \multirow{2}{*}{0.751} & \multirow{2}{*}{0.386} \\
\hline Sufficient Fruit/Vegetable consumption & 6 & 20 & 26 & & & \\
\hline Obesity & 0 & 8 & 8 & $2 \mathrm{E}-9(2 \mathrm{E}-9-2 \mathrm{E}-9)$ & 3.717 & 0.054 \\
\hline Family history & 4 & 13 & 17 & $1.52(0.26-8.73)$ & 0.357 & 0.55 \\
\hline
\end{tabular}


Smoking

\begin{tabular}{c|c} 
Current & 1 \\
\hline Past & 8
\end{tabular}

$36.00(4.18-310.15)$

20.487

0.001

Key: OR-Odds ratio; X²-Chi square; WHR-Waist-hip ratio; HDL-c: High density lipoprotein cholesterol; LDL-c: Low density lipoprotein cholesterol; E-7: x 10-7; E-9: $\times 10-9$; E5: $\times 10^{5}$

Table 4: Proportion of CV risk factors in the control group based on gender.

\begin{tabular}{|c|c|c|c|c|c|c|c|}
\hline \multirow{2}{*}{\multicolumn{2}{|c|}{ Cardiovascular Risk Factor }} & \multicolumn{2}{|c|}{ HIV Seronegative } & \multirow{2}{*}{$\begin{array}{c}\text { Total } \\
N=60\end{array}$} & \multirow{2}{*}{$\begin{array}{c}\text { OR } \\
(95 \% \mathrm{CI})\end{array}$} & \multirow{2}{*}{$\mathbf{X}^{2}$} & \multirow{2}{*}{ P-value } \\
\hline & & Males $(n=39)$ & Females $n=(21)$ & & & & \\
\hline \multicolumn{2}{|c|}{ Hypercholesterolemia } & 2 & 0 & 2 & $1.6 \mathrm{E}-7$ (1.6E-7-1.6E7) & 1.114 & 0.291 \\
\hline \multicolumn{2}{|c|}{ Hypertriglyceridemia } & 8 & 4 & 12 & $0.78(0.07-9.45)$ & 0.018 & 0.892 \\
\hline \multicolumn{2}{|c|}{ Increased LDL-c } & 4 & 2 & 6 & $0.99(0.03-30.72)$ & 0.008 & 0.928 \\
\hline \multicolumn{2}{|c|}{ Decreased HDL-c } & 27 & 13 & 40 & $0.95(0.18-5.14)$ & 0.33 & 0.566 \\
\hline \multicolumn{2}{|c|}{ Obesity/Overweight } & 14 & 12 & 26 & $2.02(0.32-12.63)$ & 2.509 & 0.113 \\
\hline \multicolumn{2}{|c|}{ Diabetes mellitus } & 4 & 1 & 5 & $3.34(0.11-103.37)$ & 0.539 & 0.463 \\
\hline \multicolumn{2}{|c|}{ Hypertension } & 10 & 9 & 19 & $0.55(0.06-4.96)$ & 1.87 & 0.172 \\
\hline \multicolumn{2}{|c|}{ Alcohol excess } & 6 & 0 & 6 & $8 \mathrm{E} 6(0.000$-no value $)$ & 3.59 & 0.058 \\
\hline \multicolumn{2}{|c|}{ Older age } & 6 & 4 & 10 & \multirow{2}{*}{$0.77(0.19-3.12)$} & \multirow{2}{*}{0.132} & \multirow{2}{*}{0.717} \\
\hline \multicolumn{2}{|c|}{ Younger age } & 33 & 17 & 50 & & & \\
\hline \multicolumn{2}{|c|}{ Physically inactive } & 6 & 1 & 7 & $0.21(0.01-3.78)$ & 1.495 & 0.222 \\
\hline \multicolumn{2}{|c|}{ Abnormal WHR } & 8 & 13 & 21 & $\begin{array}{c}0.09 \\
(0.02-0.50)\end{array}$ & 10.28 & 0.001 \\
\hline \multicolumn{2}{|c|}{ Abdominal obesity } & 2 & 11 & 13 & $0.03(0.00-0.32)$ & 17.958 & $<0.001$ \\
\hline \multicolumn{2}{|c|}{ Insufficient Fruit/Vegetable consumption } & 31 & 13 & 44 & \multirow{2}{*}{$0.51(0.13-2.10)$} & \multirow{2}{*}{2.158} & \multirow{2}{*}{0.142} \\
\hline \multicolumn{2}{|c|}{ Sufficient Fruit/Vegetable consumption } & 8 & 8 & 16 & & & \\
\hline \multicolumn{2}{|c|}{ Obesity } & 5 & 7 & 12 & $2.46(0.20-31.08)$ & 3.59 & 0.058 \\
\hline \multicolumn{2}{|c|}{ Family history } & 4 & 5 & 9 & $0.16(0.01-2.39)$ & 1.967 & 0.161 \\
\hline \multirow{2}{*}{ Smoking } & Current & 6 & 0 & 6 & \multirow{2}{*}{ 1E9 (1E9-1E9) } & \multirow{2}{*}{10.769} & \multirow{2}{*}{0.001} \\
\hline & Past & 9 & 0 & 9 & & & \\
\hline
\end{tabular}

Key: OR-Odds ratio; X²-Chi square; WHR-Waist-hip ratio; HDL-c: High density lipoprotein cholesterol; LDL-C: Low density lipoprotein cholesterol; E6: $\times 10^{6}, \mathrm{E} 9: \times 10^{9}, \mathrm{E}-7$

Following a reclassification of the study participants with the use of D.A.D risk calculator, 73\% of them in the test group had a low

or Stroke) in 5 years, 25\% had a moderate risk and $2 \%$ had a high risk Figure 1.

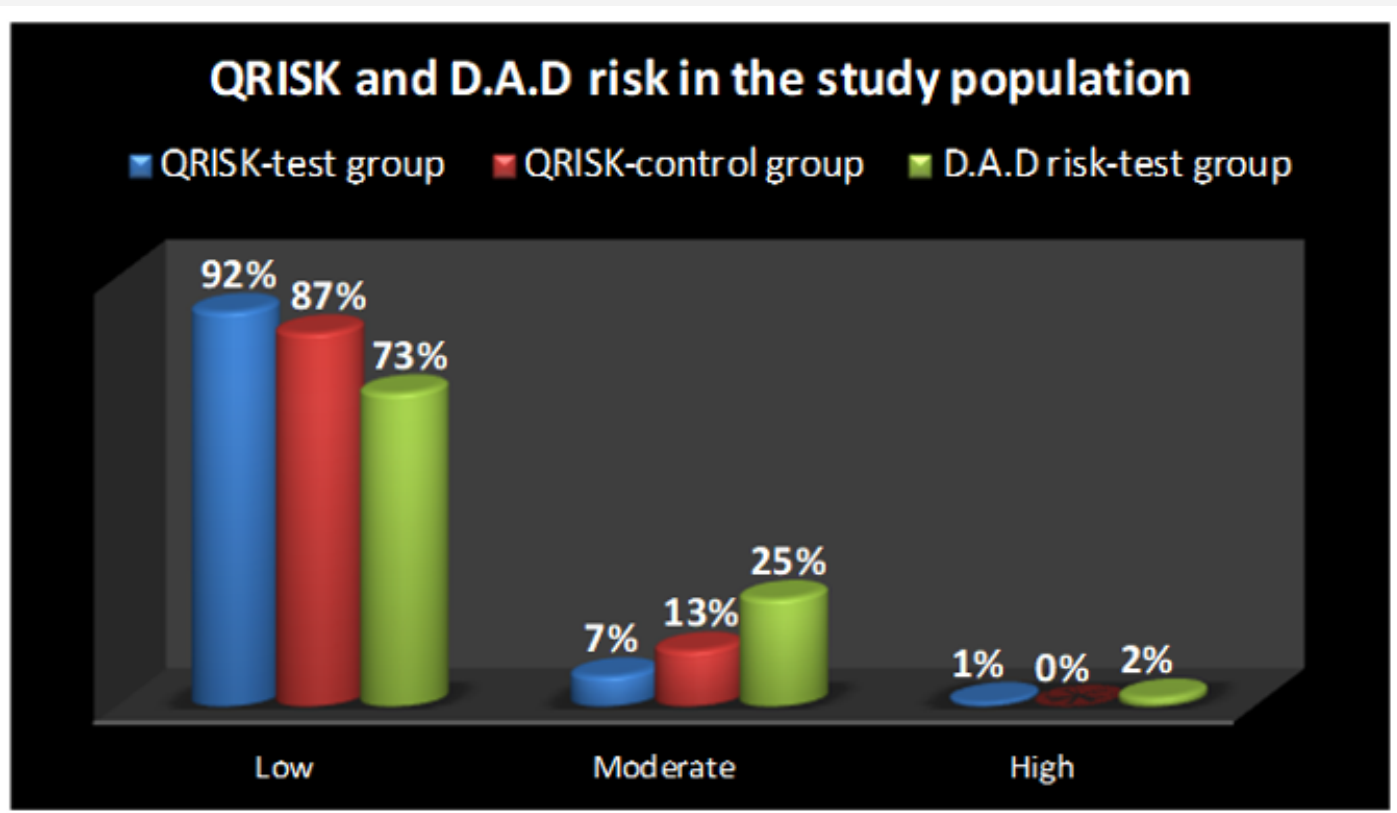

Figure 1: Distribution of Cardiovascular risk among study participants. 
More participants 12/52 (23\%) from the Tenofovir/Lamivudine /Efavirenz class (and 1/52 - 2\% was at high cardiovascular risk) were at moderate risk compared to those $4 / 18$ (22\%) of the class, Zidovudine/Lamivudine/Nevirapine Figure 2.

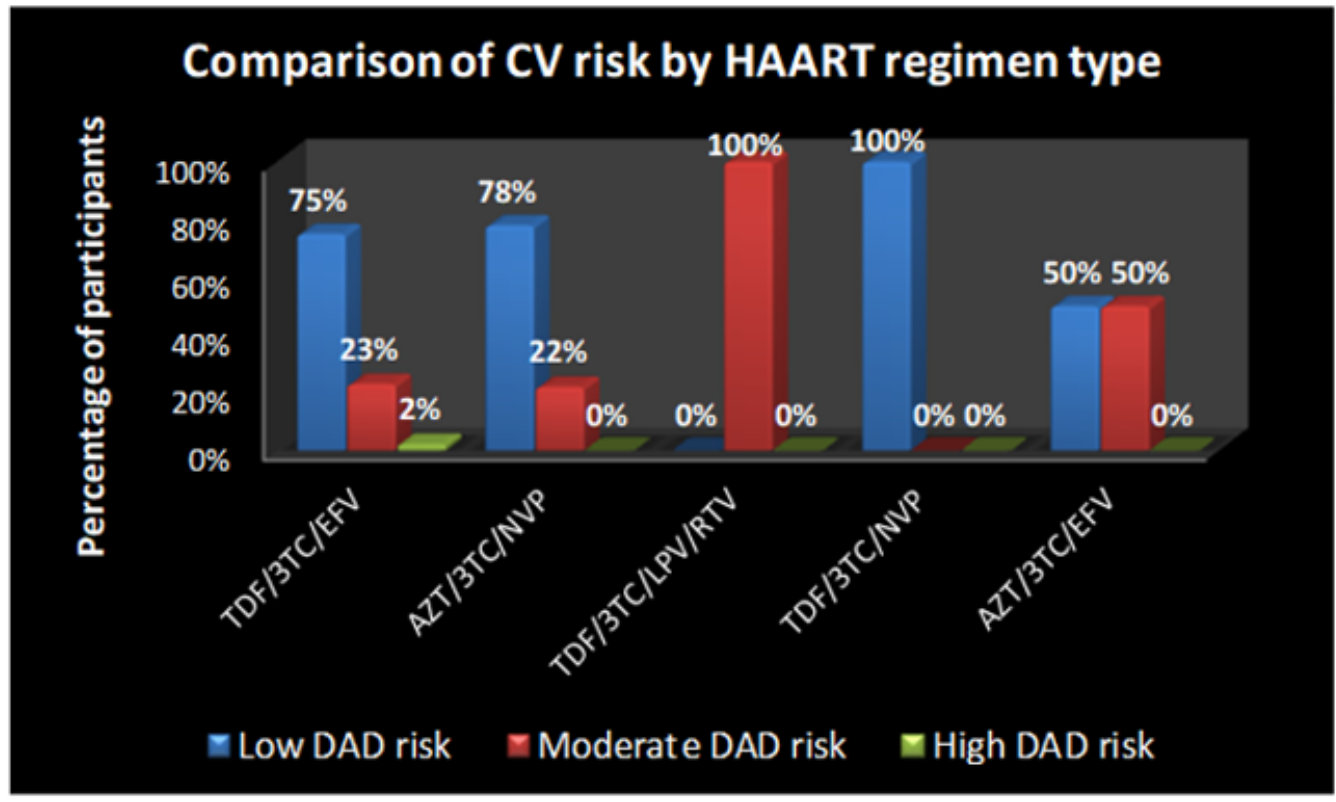

Figure 2: Comparison of CVD risk in the test group using D.A.D risk calculator based on type of HAART regimen.

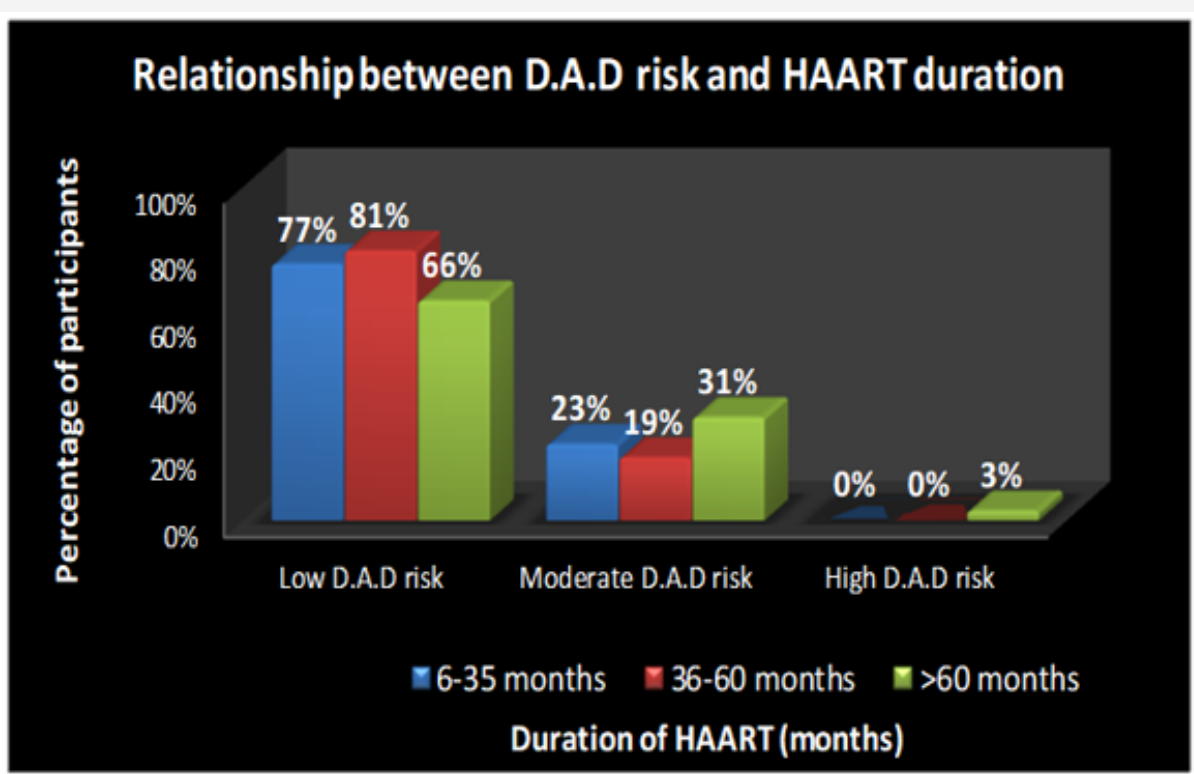

Figure 3: Comparison of a 5-year cardiovascular risk and HAART duration.

$31 \%$ of participants on HAART for more than 60 months had a moderate risk compared to $23 \%$ of participants on HAART for 6 to 35 months who had a moderate cardiovascular risk Figure 3.

\section{Discussion and Conclusion}

In this study, the most prevalent cardiovascular risk factor was decreased HDL-c with a recorded prevalence of $84.4 \%$ higher than that reported in a study among HIV patients in Buea and Limbe, Cameroon in which the prevalence of decreased HDL-c was $14.4 \%$ [10]. This difference could be owing to the fact that the previous study studied both HAART naïve and HAART experienced patients while our study studied both HAART experienced patients and HIV sero-negative persons. Our prevalence was also higher than that found in a Latin American cohort study of HIV patients on HAART in which the prevalence of decreased HDL-c was 49.5\% [11], but ties with a study conducted in Cape town, South Africa by Joel et al [12]. HDL is a cholesterol scavenger that picks up excess cholesterol from the blood and takes it back to the liver. The lower the HDL levels, the higher the risk of hypercholesterolemia and hence increased CVD risk. HAART increases lipid levels, but HDL cholesterol may not return to normal thus a high prevalence of HDL cholesterol [13]. The prevalence of insufficient vegetable or fruit consumption, $68.9 \%$ in this study was lower than that of $95.5 \%$ reported in Polokwane, South Africa by Felistas et al [7]. The prevalence of insufficient vegetable or fruit consumption is again lower than that reported from a cross-sectional study in Nepal among HIV patients 
on HAART in which the prevalence of insufficient fruit or vegetable intake was $90.0 \%$ [14]. Most participants in our study spoke about irregular availability of fruits and vegetables in the areas where they live.

Obesity or overweight was observed in $45.9 \%$ of the participants. This prevalence was nearly similar with that gotten in an Indian cross-sectional study of HIV patients on HAART, HAART-naïve HIV patients and HIV negative subjects in which the overall prevalence of obesity or overweight in these three groups was $41.8 \%$ [15]. This is also higher than that of $26.2 \%$ reported in Tanzania by Gibson et al [16]. Being overweight removes or reduces the suspicion of HIV positivity and stigma and allows acceptability and integration into the society. Of the 135 participants, 69 (92.0\%) were at low risk, $5(6.7 \%)$ were at moderate risk and $1(1.3 \%)$ were high risk using the QRISK2-2016 equation. Following a reclassification of $19 \%$ subjects from the low-risk category to the moderate-risk category, $55(73.3 \%)$ were at low risk, $19(25.3 \%)$ at moderate risk and 1 $(1.4 \%)$ at high risk using the DAD risk equation. These findings therefore indicate that HIV sero-positive patients on HAART are at a higher risk of developing cardiovascular diseases compared to HIV sero-negative individuals. Participants on TDF+3TC+LPV+RTV had the highest cardiovascular risk followed by those on $\mathrm{TDF}+3 \mathrm{TC}+\mathrm{EFV}$, $\mathrm{AZT}+3 \mathrm{TC}+\mathrm{NVP}$, and TDF+3TC+NVP, respectively, with no statistically significant difference between them $(\mathrm{P}=0.667)$. The impact of protease inhibitors in causing dyslipidaemia explains why only those on protease inhibitors were at highest risk for cardiovascular events [17-19]. Participants on HAART for more than 60 months (5 years) were at greatest risk of developing a coronary heart disease compared to those on HAART between 6-35 months ( $<3$ years) and 36-60 months (3-5 years). This would suggest that cardiovascular risk increases with duration on HAART. Despite this trend, several studies have shown that cardiovascular risks are higher in persons that are HIV sero-positive compared to those who are sero-negative and that this risk reduces once antiretroviral therapy is started [2023].

\section{Acknowledgement}

The authors appreciate the contributions made by the Chief Medical officer and laboratory staff at the Tiko Central Clinic and Cottage hospital. We are also grateful for the collaboration of the HAART treated HIV infected and HIV seronegative participants in Tiko Central Clinic and Cottage hospital.

\section{Conflict of Interest}

No conflict of interest.

\section{References}

1. Mansueto GN, Ricardo Z, Carlos B (2013) A literature review on cardiovascular risk in human immunodeficiency virus-infected patients: implications for clinical management. Braz J Infect Dis 17(6): 691-700.

2. Sandra CF, Marina BM, Bolanle O, Papa SS, Marco V, et al. (2013) HIV Infection and Cardiovascular Disease. Sci World J Pp. 1-3.

3. Monika BJ, Anna P, Joanna G, Agnieszka Ś, Urszula R, et al. (2013) Metabolic complications and selected cytokines in HIV-infected individuals. Pol Arch Med Wewn 124(1-2): 27-35.
4. Paul BA, Cameron H (2014) The Assessment and Management of Coronary Artery Disease in Patients with HIV/AIDS. J AIDS Clin Res 5(3): 1-7.

5. Joel C, Luciana MF, Sérgio PB, Celso S (2015) The Impact of Modern Antiretroviral Therapy on Lipid Metabolism of HIV-1 Infected Patients. Trends in Basic and Therapeutic Options in HIV Infection-Towards a Functional Cure. Intech Pp. 129-182.

6. Busari OA, Adeyemi AO, Agboola SM, Busari OE (2009) Insulin resistance in HIV disease: aetiopathogenesis and treatment. African Journal of Diabetes Medicine 9-10.

7. Felistas M, Marianne A, JeanPierre Vg, Robert C (2015) Assessment of cardiovascular risk factors in people with HIV infection treated with ART in rural South Africa: a cross sectional study. AIDS Res Ther 42(12): 1-10.

8. ClinRisk (2016) Welcome to the QRISK®2-2016 risk calculator.

9. HIV Pharmacovegilance. Risk Evaluation Tools.

10. Dickson Shey Nsagha, Jules Clement Nguedia Assob, Anna Longdoh Njunda, Elvis Asangbeng Tanue, Odette Dzemo Kibu, et al. (2015) Risk Factors of Cardiovascular Diseases in HIV/AIDS Patients on HAART. Open AIDS J 9: 51-59

11. Nery MW, Martelli CM, Silveira EA, de Sousa CA, Falco Mde O, et al. (2013) Cardiovascular Risk Assessment: A Comparison of the Framingham, PROCAM, and DAD Equations in HIV-Infected Persons. Sci World J Pp. 1-9.

12. Joel AD, Naomi SL, Ian LR, Miguel L, Gary M, et al. (2016) Anti-Retroviral Therapy Increases the Prevalence of Dyslipidae mia in South African HIV-Infected Patients. Plos One 11(3): 1-13.

13. Eoin RF, Patrick WG (2011) HIV and HAART-Associated Dyslipidaemia. Open Cardio vasc Med J 5: 49-63.

14. Nirmal A, Debbi M, Padam S (2014) Cardiovascular risk factors among people being treated for HIV in Nepal: a cross-sectional study. Jcrhap 4(1): 22-36.

15. RAB C, Rupali P, Abraham OC, Kattula D (2013) Does first line antiretroviral therapy increase the prevalence of cardiovascular risk factors in Indian patients? A cross sectional study. Journal of postgraduate Medicine J Postgrad Med 59(4): 258-262.

16. Gibson BK, Mary TM, Ester SN, Godfather D Kimaro, Akili K Kalinga, et al. (2014) Magnitude and risk factors of non-communicable diseases among people living with HIV in Tanzania: a cross sectional study from Mbeya and Dar es Salaam regions. BMC Public health 14: 904.

17. Friis-Møller N, Reiss P, Sabin CA, Weber R, Monforte Ad, et al. (2007) Class of antiretroviral drugs and the risk of myocardial infarction. N Engl J Med 356(17): 1723-1735.

18. Klein D, Hurley LB, Quesenberry CP Jr, Sidney S (2002) Do protease inhibitors increase the risk for coronary heart disease in patients with HIV-1 infection. J Acquir Immune Defic Syndr 30: 471-477.

19. Durand M, Sheehy O, Baril JG, Lelorier J, Tremblay CL, et al. (2011) Association between HIV infection, antiretroviral therapy, and risk of acute myocardial infarction: a cohort and nested case-control study using Quebec's public health insurance database. J Acquir Immune Defic Syndr 57: 245-253.

20. Lars GH, Heiner CB (2014) HIV infection and cardiovascular disease. Eur Heart J 35: 1373-1381.

21. Islam FM, Wu J, Jansson J, Wilson DP (2012) Relative risk of cardiovascular disease among people living with HIV: a systematic review and metaanalysis. HIV Med 13: 453-468.

22. Ithoff KN, Gange SJ (2013) A critical epidemiological review of cardiovascular disease risk in HIV-infected adults: the importance of the HIV-uninfected comparison group, confounding, and competing risks. HIV Med 14: 191-192.

23. Triant VA, Lee H, Hadigan C, Grinspoon SK (2007) Increased acute myocardial infarction rates and cardiovascular risk factors among patients with human immunodeficiency virus disease. J Clin Endocrinol Metab 92: 2506-2512. 